\title{
Evaluating the efficacy of psychodynamic treatment on a single case of autism. A qualitative research
}

\author{
Marta Vecchiato, ${ }^{1}$ Chiara Sacchi, ${ }^{1}$ Alessandra Simonelli, ${ }^{1}$ Nicola Purgato ${ }^{2}$ \\ ${ }^{1}$ Department of Developmental and Social Psychology, University of Padua, Padua; ${ }^{2}$ Educational and Rehabilitation Centre for Minors \\ Antenna 112, Venice, Italy
}

\begin{abstract}
Autism spectrum disorder refers to a group of diseases determined by multiple conditions and primarily defined on the basis of behavioral patterns. The literature and guidelines provide indications regarding adequate treatments, underlying how psychologically and behaviorally structured interventions, should be considered the best programs. Anyway, there is still a scarcity of studies evidencing the effectiveness of therapeutic and developmental approaches situated in a psychodynamic framework and researches aimed to evaluate the quality of psychodynamic interventions on autism are rare. The present study illustrate a qualitative research on the single-case intervention with an autistic adolescent, admitted to the Educational - Rehabilitation Centre Antenna 112. The Centre bases its intervention on a specific psychodynamic approach, Lacanian Psychoanalysis, named Pratique à Plusieurs. The efficacy of the psychodynamic intervention is evaluated by monitoring the therapeutic process with the adolescent from his admission. The evaluation took place in three different stages of the intervention: at the beginning of the treatment, after 6 months and after 12 months. In particular, the level of adaptive behaviors (Vineland Adaptive Behavior Scale), Social Communication (Social Communication Questionnaire), and the seriousness of behavioral patterns, specific for the autism disorders (Childhood Autism Rating Scale) have been assessed. Results highlight that the psychodynamic setting of the Centre and the therapeutic intervention, which takes place in it, foster an improvement of adaptive behavior, such as life skills and socialization. Limitations of the present study and clinical implications regarding residential psychodynamic treatments in cases of autism disorders are discussed.
\end{abstract}

Key words: Autism spectrum disorders; Pratique à Plusieurs; Efficacy; Treatment.

\section{Introduction}

Autism spectrum disorders (ASDs) represent a heterogeneous class of diseases, primarily defined on the basis of behavioral patterns. In particular, ASDs are mainly

Correspondence: Marta Vecchiato, Department of Developmental and Social Psychology, University of Padua, Padua, Italy.

Tel: +39.049.8276500 - Fax: +39.049.8276547.

E-mail: marta.vecchiato@gmail.com

Citation: Vecchiato, M., Sacchi, C., Simonelli, A., \& Purgato, N. (2016). Evaluating the efficacy of psychodynamic treatment on a single case of autism. A qualitative research. Research in Psychotherapy: Psychopathology, Process and Outcome, 19(1):49-57. doi: 10.4081/ripppo.2016.194

Received for publication: 3 August 2015.

Revision received: 21 Ocotber 2015.

Accepted for publication: 12 January 2016.

This work is licensed under a Creative Commons Attribution NonCommercial 4.0 License (CC BY-NC 4.0).

CCopyright M. Vecchiato et al., 2016

Licensee PAGEPress, Italy

Research in Psychotherapy:

Psychopathology, Process and Outcome 2016; 19:49-57

doi:10.4081/ripppo.2016.194 characterized by delay and deviance in the development of social interaction, communications and cognitive skills; repetitive behaviors, interests and activities (American Psychiatric Association, 2000).

Due to the complexity of the impairment involved in the autistic condition, one of the most controversial of all topics in the ASDs literature is represented by the types of treatments applied and selected up to date (Matson \& Williams, 2015). In fact, parents of autistic children often engage in different treatments, with an average of 7-8 kinds (Goin-Kochel, Myers, \& Mackintosh, 2007; Stephenson, Carter, \& Kemp, 2012), and tries lots of alternative interventions (Maurice, Mannion, Letso, \& Perry, 2001; Metz, Mulick, \& Butter, 2005; Simsek \& Koroglu, 2012; Wong \& Smith, 2006).

For these reasons, researches directed to evaluate the efficacy of interventions in cases of autism disorders are needed. With this aim, in recent years, professional groups and state health departments have reviewed available interventions for autism and have developed guidelines on recommended treatments. However, both in international and national guidelines, psychodynamic approaches and interventions are scarcely represented. Moreover, there is still a paucity of studies evidencing the effectiveness of therapeutic and developmental approaches situated in a psychodynamic framework and researches aimed to evaluate the quality of psychodynamic intervention on autism are rare. 
First of all, while autism has drawn interest from the beginnings of psychoanalytic theory, the contemporary literature makes limited reference to autism and has not widely embraced it as a psychological condition to be conceptualized or treated (Emanuel, 2015). However, parents look for psychoanalytical treatments for their children, which often happens after they have been through several ineffective ways of treatment which have not satisfied them (Freire \& Malcher, 2014). In particular, parents' often complain about techniques used, which seem to reinforce the greater isolation of their children (Freire \& Malcher, 2014).

As a consequence, psychodynamic and psychoanalytic approaches are often chosen in a late phase, reducing the chances of a good response to the treatment (Freire \& Malcher, 2014).

The Pratique à Plusieurs was founded in 1974 in Brussels, by Antonio Di Ciaccia, psychoanalyst and member of the Lacanian School of Psychoanalysis and the World Association of Psychoanalysis, and founder of the Antenne 110 (Di Ciaccia, 2011).

This is the first structure designed for the treatment of autistic and psychotic children using Freudian and Lacanian psychoanalytic assumptions; it then have followed many other institutions: in Belgium is Le Courtil (Leers); in France are the Centre of Research and Therapeutic Nonnette, the day centers Mezza-Luna, Podensac and Isola Verdein Cadillac, the Consultation Center Clos Benard in Aubervilliers; in Italy is the community Due Pini in Bologna, the community Antenna Gertrude Beolchi and two day centers Antennina in Milan, the community Le Villette in Saluggia, the associations Violetta in Fano, Pio-Pao in Ancona, Il Cortile in Rome, La Ginestra in Valmontone and the Educational - Rehabilitation Centers for children with autism and psychosis Antenna 112 and Antennina in Marghera (Venice), specific to this research, active since 1997.

According to the Pratique à Plusieurs, psychoanalysis, therefore disconnected from its traditional setting, is an exclusive practice of attention focused on the individual and a place where is it possible to build something together (Di Ciaccia, 2006).

This is done by capturing the clinical course of the autistic child and through their use as a starting point for an articulated educational and rehabilitation work. The project is therefore based on the relationship, because only within the relationship it is possible to develop a change.

From these assumptions, it was necessary to create a new place, where individuals could express themselves intimately without any didactic intent, focused only on the understanding of the logic of the individual, aimed to promote the creation of the subject (Miller, 2001).

The Pratique à Plusieurs is implemented through a multidisciplinary team of psychologists, psychotherapists, educators, social and health workers, social assistants, psychiatrists, who work according to the need of chil- dren's understanding, through a path characterized by four steps, more logical than chronological.

Shown below are the four phases, explained by Purgato (Egge, 2006; Purgato, 2012).

The first step - pacification - is aimed to remove the anxiety of the child welcoming him/her within a regulated and structured environment. In this way it is possible to enable him/her to abandon his/her defenses and to reduce symptomatic answers, such as acting out against the self or the others, stereotypy, hyperactivity, and moments of anxiety. No one ignores the response that everyone brings when it comes, nor the will to ignore it, but it is necessary to give it the right value, to know how to listen and accompany.

The second step is called construction. Starting from the personal characteristics that each person brings (an object, a word/doggerel, an obsessive ritual, stereotypy), a work has to be made in order to insert them in activities, to give them a sense and to direct them so that they can progressively acquire a wider meaning; in this way they will allow to develop skills and abilities of the subject leading him/her the construction of a personal knowledge (the so called islands of competence). It is critical at this stage the acquisition of the ability to go through the request to the other, learning how to make a request that expresses a desire, how to tolerate the waiting time, the process of turn-taking and frustration.

Once that the pacification has been obtained and the individual has articulated a personal knowledge, the work focuses on openness to learning (third step: learning). Since within the dual relationship the Other is perceived as a persecutor, and consequently excluded through the closure in him/herself from the part of the child, it is useful to draw upon the method of triangulation, i.e. inserting a third element that puts a barrier between the child and the Other and separates them; for example, instead of addressing directly to the child, it is possible to ask a question to another operator or to another child, allowing the word to circulate among workers and children. In this way it is possible to transmit social norms, adaptive behaviors, and other forms of learning, also of scholastic kind.

The forth step is the social bond. Indeed, through a network that involves parents, teachers, social and health workers and other figures in the child's life, the team works to improve the children's social skills, in order to allow school integration, the frequentation of socialization places (e.g., swimming pool, game room and groups sports activities), the resumption of a normal life when they come home, and an increase in the management of relationships with peers in outside school contexts.

The steps are implemented in structured spaces and through scheduled workshops, including various types of activities aimed at the construction of the subject, according to an individualized project. Psycho-educational and psychomotor activities, speech therapy, the use of the personal computers and of instruments not purely analytical are also included. 
It is necessary to specify that the term individualized refers to the attention paid to the individual and that the work in the laboratories foresees small groups of children, in order to be always able to emphasize the role of the relationship. This implies an interest in the spontaneous activities of the individual, so that he/she could be lead through a process of learning inscribed within an interactive frame (Boudard, 2011). Even the aim of personal autonomy, beloved to the community, is taken from a perspective with the Other: autonomy alone is not enough if it is not contextualized.

Moreover, every moment is considered useful to develop the potential of the individual: contrary to what happens in other types of institutions, in fact, there is no separation between treatment and daily life activities (Brousse, 2011).

In this sense, all routine activities are fundamental since it is not always and not exclusively on the occasion of the re-education workshops that children face what is their problem (Boudard, 2011).

On the other hand, nothing in the children's life is entrusted to the case; all the moments are structured in a frame of space and time, indispensable to provide a stable continuity to the subject. It is provided a very precise time management in order to create a degree of freedom inscribed in a frame of meaning. The structure allows the learning of Community rules and the management of the frustration of immediate satisfaction, as well as the definition of a place where the child can feel safe, finding their subjective place. The timetables, the places and the people involved in the activities are well defined and when changes occur, these are promptly communicated to the coordinator, the reference point of children and staff.

Although everyday life is stable it is also necessary that the child could be followed by operators in an interchangeable way. In this way, the formation of a dyadic exclusive relationship is avoided and the child is allowed to experience more approaches, while still maintaining the same common strategies.

This aspect is directly connected to the learning phase, in which the use of triangulation occurs. According to the principle that, in the dual relationship, the Others for the autistic child have a valence of persecution, the introduction of the third element, reduces anxiety, and it becomes more acceptable to the subject (Boudard, 2011).

Thus, this treatment does not foresee a common method for all the children, since each child is considered in his/her subjectivity, a sort of visiting card that allows building the therapeutic work.

It is the same Temple Grandin, high functioning autistic, who explains the importance of accepting manias typical of autism: Many children with autism become fixated on various subjects. Some teachers make the mistake of trying to stamp out the fixations. Instead, they should broaden it and channel it into constructive activities. For example, if a child becomes infatuated with boats, then use boats to motivate him to read and do much. Read books about boats and do arithmetic problems on calculating boat speed. Fixations provide a great motivation. [...]. Teachers need to help autistic children develop their talents. I think there is too much emphasis on deficits and not enough emphasis on developing abilities. (Grandin, 2006)

This is exactly what the Pratique à Plusieurs proposes, namely to make the manias of children their visiting card. Children are then received in their singularity, not eliminating their bizarre interests or behaviors, but by helping them to develop more of them.

In order to better exemplify how the Pratique à Plusierus works, a short clinical example is provided as follows. It refers to a female patient, who already completed her treatment in the Centre. At the beginning of the intervention the young patient could not stand new stimulus outside her solid routine. Initially, the work consisted in trying to ritualize the arrival and the leaving time in the community, avoiding any possible unexpected noise or event. This was done by reserving her a special room, the yellow room where she could feel secure and comfortable. She was thus received accepting her particular necessities (that could have otherwise been defined as manias) and starting from these same strategies, it has been possible to overcome these transition moments and to move forward. For example, since she appeared interested in magazines with photos concerning cooking, it has been decided to project a collage-atelier where pictures of food and dishes were cut, pasted on paper and hung on the walls of her room. Later on, a new atelier was suggested, where the dishes of the pictures were actually prepared and eaten with the other children during tea break. Although during the first weeks she prepared the meal alone with the professional, later she gradually accepted the presence of another child; at the beginning she simply watched the professional preparing the meal, but later she became active part in the preparation, indicating the different ingredients at the right time: milk, butter, eggs. All these steps were initially rigidly unfolded in the yellow room; anyway, one day she became particularly interested in the baking phase she decided to get in the kitchen. Since from this first moment and movement, other movements were possible, exploiting new interests or abilities noticed by the professionals: in the puzzle room, where she made puzzles progressively more complex; in the music room, where she chose her favorite songs and musical fairy tales, until the walking-into-town atelier, where unexpected noises and events seemed less disturbing than once. In this way, beginning from an initial symptom, it was possible not only to develop abilities, but also to diversify relationships and to overcome her manias.

As far as it concerns the parental role in the Pratique à Plusieurs, Di Ciaccia emphasizes that the place reserved for the family is one of the decisive points in the care of children (Egge \& Grigoletto, 2000; Baio, 2011).

According to Baio (2011), there could be two extreme 
positions adoptable when working with parents: some treatments give them a big load of responsibility in the result, which involves an expensive work on themselves and taking multiple roles (parent, but also an educator, pedagogue or therapist); other interventions consider the caregiver, but only for causative reasons, therefore excluding them from the treatment.

In the Pratique à Plusieurs the focus of the work resides in considering parents as subjects the holders of knowledge of the child. Not only because they are actually able to provide necessary information to the team for the understanding of the child's structure, but also because in this way their privileged place within the treatment is legitimized.

When they entrust their children, in fact, the caregivers are full of fears, guilt, feelings of inadequacy and failure resulting from their sense of not being able to care their children. We must therefore receive them in the project, involving them, informing them about the objectives and strategies for pursuing these objectives.

The change does not include only the children then, but their families too: along the way, parents understand how to act differently with respect to the past, enthusing for small achievements (Baio, 2011).

As regards the present study it will be presented a single case of application of the Pratique à Plusieurs. In fact, since autism presents heterogeneity in its manifestations, the single case design represents the more informative research design (Bulkeley, Bundy, Roberts, \& Einfeld, 2013). Moreover, single case design enable to build individualized considerations on the treatment which are the best way to develop change in the course and individualized variation in intervention for young children with ASD, that is regarded as best practice (Barton, Lawrence, \& Deurloo, 2012; Delmolino \& Harris, 2012; Strain, Schwartz, \& Barton, 2011).

\section{Methods}

\section{Case description}

$\mathrm{M}$. is a 16-year-old Italian guy who joined the psychodynamic-oriented treatment and environment of the Centre Antenna 112 in September 2013. At the admission the Autistic Disorders Interview (ADI-R; Rutter, Le Couteur, Lord, \& Faggioli, 2005) was administered to both parents together. The ADI-R confirmed the diagnosis of autism and furnished anamnesis information regarding M.'s development.

Parents' reports that from the earlier stage of his life, M. presented delay in the motor development and always showed difficulties in walking. At the age of two years $\mathrm{M}$. was hospitalized for the evaluation of a psychomotor delay, which excluded the presence of organic causes.

M. received the diagnosis of Not Specific Disorders of Psychological Development for the first time at the age of four years, when a significant decrease in the linguistic and motor development was observed. He joined the childcare and after the primary school, aggressive behaviors toward peer were observed and forced parents to retire him from school.

Before being admitted to the Centre Antenna $112 \mathrm{M}$. was involved in physiotherapy interventions and logaoedic treatments.

At the moment of admission to the Centre, M. presented frequent aggressive behaviors against other children, with bites, punches and kicks, and strong aggressive crisis with implacable shouts at the occurrence of light noises, such as sneezes, weeping or coughing. Moreover, M. showed stereotyped routines. As regards the motor domain, M. had strong difficulties in coordinating limbs movements and motor impairments, such as toe-walking and unbalanced walking. M.'s verbal communications were absent, with the exception of very limited words produced with a communicative intention in rare occasions, as referred by both parents.

From his admission at the Centre, simultaneously to the Psychodynamic treatment, M. receives a pharmacological treatment composed by: atypical antipsychotic (Abilify, $10 \mathrm{~mL}$ once a day) and anticonvulsant (Depakin, $300 \mathrm{mg} / \mathrm{mL}$ three times per day).

From awakening until bedtime, the day of $\mathrm{M}$. is scheduled in one-hour ateliers, individual or collective, each one supervised by a different operator.

Every day is characterized by the same timetables but filled with different activities. At the same time the ateliers remain fixed each week. In this way, every Monday from 9.30 to $10.30 \mathrm{M}$. will have the same atelier with the same operator, and so on. This structuring space-time allows $\mathrm{M}$. to regain a stable continuity having a retaining frame.

The alarm clock is at 8:00 am. He takes a shower, has breakfast and takes medicines. The first two ateliers, from 9.30 to 11.30 , last one hour each one. During the school period, in these two hours M. attends middle school, followed by a special education teacher. There is also a snack together and following another atelier that last until 13.00, the lunch hour. At 14.00 medicines are administered again and M. begins other two atelier (of one hour each) until 16.00 , where there is a pause for a snack. Other two ateliers follow then, entertaining M. until dinnertime.

Every moment of the day, whatever it is, it is a time of work, since it involves effective learning and enrichments, a sequence of symbolic imagery that allows them to understand the world and to find their place. The moment of the toilet is not just a space where personal hygiene is performed, but it becomes a real workspace in which personal autonomy, space-time orientation, the knowledge of body and fine motor skills, the differentiation between hot-cold water, the knowledge on how to undress and play and the learning of words and language are gradually acquired.

The ateliers are built depending on the interests of $\mathrm{M}$. As a matter of fact, when he joined the community, M. brought various visiting cards. In a short time the operators realized how much $\mathrm{M}$. liked the rides, since they are rich 
in lights and sounds that attract him a lot. Starting from this interests the ateliers were built specifically for him: in one of them he draws and colors the rides trying to use different materials from time to time in order to expand his creativity, in another one he has fun watching videos of the rides on the computer, in another one he had the possibility to join rides in local fests, when in the neighborhood, and, in another atelier he goes printing selected photos.

The rides were not his only visiting card, music was another important interest. M., in fact was attracted by many sounds, and he developed the ability to recognize sounds of different musical instruments. From this interest, it was built a real music room where, with the help of operators, playing various musical instruments, $M$. learned gradually how to play the drum, the piano and the guitar.

Moreover, when M. joined the community he proved to be able to recognize some letters, and thanks to this it was possible to build a reading and writing atelier in which, guided by an operator, we try to expand its skills, through the writing activity both with the pen and with a computer, until arriving at reading simple books for children.

At the beginning these ateliers were individual because of his aggressive nature, but across the time M. can progressively participate in ateliers with a couple of patients. In this way not only his skills have been expanded, but the relationships have been diversified too. Using team ateliers it was possible to create new-shared interests, such as the kitchen atelier, in which M. helps making sweets or dinner with another guy and an operator. In particular, he likes counting the ingredients, and mixing them. Then there are the shopping atelier where, he goes to buy bread, or essential stuff, accompanied by an operator and another boy.

During the weekend M. receives visits from his parents, with whom he goes out half day on Saturday and half day on Sunday. Time and space become structured also with parents, in order to provide a greater containment to M. Therefore, also with his parents he goes to see the rides, to the supermarket to do the shopping, he goes walking or to the hairdresser.

Thanks to this collaboration, a very strong network has been established with the parents too and $\mathrm{M}$. is benefiting from that.

Interviews with parents are conducted monthly, either because they are deemed to be subject holders of knowledge of M., and therefore able to provide necessary information to the team for the knowledge of the boy's structure, but also in order to reach a joint assessment of the work done with M., and to accommodate their doubts and concerns resulting from their experiences as parents of an autistic boy and to provide them with guidance on how to deal with the child's difficulties.

\section{Procedure and measures}

The research is composed by a longitudinal design in which adaptive behaviors, social communication and the seriousness of behavioral patterns, specific for autism disorders, are assessed. In particular, data were collected at the beginning of the treatment, after 6 months and after twelve months in order to evaluate possible improvements. At each stage of the research, assessment tools were individually administered to two different operators, weekly involved in activities with $\mathrm{M}$. on an average of twenty hours.

\section{Measures}

Vineland Adaptive Behaviors Scales (VABS; Sparrow, Balla, \& Cicchetti, 1984; Balboni \& Pedrabissi, 2003). It is a psychological tool, which could be used in its semistructured interview form as so as a rating scale. It is designed for the assessment of adaptive behaviors and the measure of deficit in such behaviors from birth to adulthood. It is composed by 11 subscales, sorted in four principal domains: Communication (Receptive, Expressive, Written), Daily Living Skills (Personal, Domestic, Community), Socialization (Interpersonal Relationship, Play and Leisure Time, Coping Skills) and Motor Skills (Gross Motor, Fine Motor). The Motor Skills domain is used for children under 6 with normative development.

The interview version requires about 20-60 minutes. Items/questions range from 0 to 2 and the scores to each subscale provide the level of age equivalent (AE).

The VABS have been shown to have strong reliability and validity (Sparrow, Balla, \& Cicchetti, 1984) and presented high levels of Cronbach's Alphas in the Italian sample: .99 in each scale, in the 14-19 years old sample (Balboni \& Pedrabissi, 2003). As regards clinical applications, in a sample of 684 autistic children reliability ranged from .93 to .99 for all the four scales (Carter et al., 1998).

Social Communication Questionnaire (SCQ; Rutter, Bailey, \& Lord, 2003; Rutter, Bailey, Lord, Cianchetti, \& Fancello, 2007). It is a parent-report questionnaire asking about characteristic autistic behaviors, in order to highlight specific symptoms of ASDs from the age of 5 years, such as specific qualitative abnormalities in social interaction with each other, qualitative abnormalities in communication and restricted, repetitive, stereotyped behavior patterns (Rutter, Bailey, \& Lord, 2003). The tool is available in two different forms: lifetime and current. The questionnaire is composed by 40 dichotomous items [yes(1)/no(2)]. The total score range from 0 to 39 , since the item 1 do not receive a score, and score 15 represents the cut off for a diagnosis of autism. It has established validity with the ADI-R and (Berument, Rutter, Lord, Pickles, \& Bailey, 1999) and good psychometric characteristics: Cronbach's alpha $=.81$ and .86 for the Italian version (Rutter et al., 2007).

Childhood Autism Rating Scale (CARS; Schopler, Reichler, \& Rochen Renner, 1986) is a 15-items rating scale, developed to identify children with autism by two years of age, and to distinguish them from children with other developmental disabilities; it can be applied to adolescents 
and adults too. The 15 items assess different areas of functioning, such as: Relation to People; Imitation; Emotional Response; Body Use; Object Use; Adaptation to Change; Visual Response; Listening Response; Taste; Smell and Touch Response and Use; Fear or Nervousness; Verbal Communication; Nonverbal Communication; Activity Level; Level and Consistency of Intellectual Response; General Impression. Each item range from 1 (normal level) to 4 (severe level). The total score provides an assessment of severity of autism, distinguishing between three levels: absence of autism (15-29.5), mild to moderate (30-36.5) and severe condition (37-60). The CARS showed high internal consistency; Cronbach's Alpha=.94 in the original version (Schopler, Reicher, \& Rochen Renner, 2002).

\section{Data analyses}

In order to evaluate the improvements on communications, adaptive behaviors and the severity of autism, both operators' reports were independently compared across the time; in particular not parametric analyses have been used at this scope.

\section{Results}

\section{Operator 1}

As regards first operator's reports, the Freedman and Cochran tests respectively revealed no significant improvements from the beginning of the intervention up to 12 months later in the severity of autistic patterns (CARS) of M. $\left[\chi^{2}(2,15)=1,111, \mathrm{P}=.574\right]$, neither in the level of social communication, SCQ [Cochran's Q $(2 ; 34)=3,5, \mathrm{P}=.174$ ].

In contrast, a significant improvement was observed in the level of adaptive behaviors (VABS) from the beginning of the treatment and the $12^{\text {th }}$ months of intervention $\left[\chi^{2}\right.$ $(2,539)=14,225, \mathrm{P}=.001]$. In particular, Wilcoxon test revealed a significant increment between the first stage of the research and the second one $(\mathrm{P}=.000)$ but not between the second stage and the third one $(\mathrm{P}=.327)$. Moreover, the improvement regarded all the three domain of adaptive behaviors; as regards the communication and daily ability areas, significant improvements are reported between the first and the second stage, $(\mathrm{P}=.003 ; \mathrm{P}=.001)$, while for the socialization domain the improvement was significant both between the first and the second stage $(\mathrm{P}=.011)$ and the second and the third one $\mathrm{P}=.005)$. As regards the mental age, obtained coding the composed scale of VABS, at t0 the operator 1's report indicate an equivalent mental age of two years and two months, while at $\mathrm{t} 1$ and $\mathrm{t} 2$ the corresponding mental age was 2 years and 8 months.

\section{Operator 2}

According to second operator's results, no significant improvements across the time were found in social communication [Cochran's $\mathrm{Q}(2,34)=4, \mathrm{P}=.135$ ] and in CARS reports $\left[\chi^{2}(2,15)=, 311, P=.856\right]$. Coherently with first operator, a significant increase along the stage of investigation were observed in the level of adaptive behaviors $\left[\chi^{2}\right.$ $(2,538)=7,601, \mathrm{P}=.022]$. However, here the significant change regards the second and the third part of the investigation, such as the improvement is observed between the $6^{\text {th }}$ month of treatment and the $12^{\text {th }}(\mathrm{P}=.005)$ while no improvements were observed from the beginning of the intervention to 6 months after $(\mathrm{P}=.510)$. In particular, a significant improvement regards the domain of daily ability $(\mathrm{P}=.019)$ and socialization $(\mathrm{P}=.006)$. As regards the equivalent mental age, at $\mathrm{t} 0$ it was of three years and four months, at $\mathrm{t} 1$ was three years and two months, and at the last stage (t2) it was of 3 years and 8 months.

\section{Discussion}

There are different reflections and considerations that can be drawn on M.'s case and from the obtained results.

First and foremost, referring to M.'s personal history, during the administration of the ADI-R the parents report that at four years of age the child had already received a diagnosis of autism, after the several assessments made following the decay of language and motor behaviors. The documents archived in the medical records of Antenna 112 state that in 2009 (at the age of 12 years old) M. was followed with periodic controls at the Autism Surgery Unit of Child Neuropsychiatry of Company City of Bologna, where he was diagnosed with Multisystem Developmental Disorder (MSDD) according to the Classification ZERO-THREE, and consequently with Pervasive Developmental Disorder-NAS (DSM-IV TR).

Since the first diagnosis received, until the entrance at the Antenna 112, M. was followed by a speech therapist and, while attending the secondary school level he was also followed by a support teacher, a OSS and a psychologist-educator. The last year of school, before being inserted in the center, he was declared not educable due to his aggressive behavior.

The first reflection comes from the observation of how early specific interventions for ASDs have not been made with $\mathrm{M}$. In fact, only after a succession of visits and assessments, just at the age of 16, he was inserted in the Educational-Rehabilitation Centre for autistic and psychotic children Antenna 112, although the first signs of problems were already noticed when the child was 2 years old.

The uncertainty and the difficulty of the case have conducted M. until age 16 without a program of intervention durable and centered on the autism disorder, making the current treatment much more complicated and difficult, given that many of the skills that are normally more malleable in children than in adolescents. In fact, in late treatments there are more difficulties and complications in removing possible social and affective impasses and the chances of good response to the intervention are lower (Freire \& Malcher, 2014). 
Early identification of autism is, today, one of the most important challenges that the scientific community is facing. It is a fundamental aspect because an early diagnosis produce early interventions which allow to work in the first years and thus to take charge of the individual in specialized facilities at an age where some developmental processes can still be changed. The complexity of early diagnosis resides both in the parent's difficulty to discriminate the difference between dysfunctional behaviors and typical development aspects (this awareness, in fact, is often belated) and in the fact that many diagnostic instruments used by professionals are not suitable for very young ages.

Referring, instead, to the results obtained from the tests, it is possible to see how significant improvements were reported by the two operators (even if sometimes in different measure) in the domains of everyday skills, adaptive behaviors and socialization. On the other hand, in the social communication did not improve along the treatment treatment.

A possible interpretation of this difference could be that. The Socialization (VABS scale) represents a broad domain, composed by different abilities. In contrast, the Social Communication could be conceived as a narrow and more specific domain of the socialization. Moreover, the Socialization scales of VABS measure the 3 areas of Interpersonal Relationships, Play and Leisure Time and Coping Skills, while the SCQ items measure specific aspects of the communication, such as linguistic anomalies and stereotypes.

Moreover, no significant changes resulted from the CARS test. Anyway, this instrument enabled us to determine the severity of the autistic pathology in M., underlining that sensory behaviors and social skills, the use of the body and objects, and the language of M. are highly dysfunctional. However it should be pointed out that the treatment was not intended to cure autism, but aimed to welcome the boy, starting from his visiting card, enhancing his interests, emphasizing his skills, and increasing the acquisition, from time to time, of new skills, trying to ensure that maladaptive manifestations resulting from the pathology could reduce.

It was also noted how the decision to administer the test to two operators, one of which is the operator of reference for the boy and the other to an operator who knows very well the guy, not only has provided a more extensive description of the patient, but has also allowed to reach a more objective perspective, not marred by the operatorpatient relationship. As we have seen from the results obtained, operators, for some items of VABS, sometimes have submitted discordant answers. A discrepancy of the answers could be due both to the selective response of $\mathrm{M}$. to two operators and to a weakness of the observational system. It was noticed, in fact, both the difficulty experienced by the operators when asked to think about the development of M.'s skills and abilities in relation to the development of skills and abilities expected from a boy of the same age with typical development (comparison required during the compilation of some VABS' items), both the difficulty of evaluation due to the complexity and the severity of the pathology. This should not be seen as a limit but as an advantage; thanks to these observations, in fact, all the operators of the center are forming through targeted equips, where the various multidisciplinary professional figures involved in the care of M., and of the other guys, bring into play their knowledge.

Also with regard to the measurement of M.'s mental age, were observed discordant results. A first explanation of this difference could be attributed to the different involvement of the two operators in M.'s activities. In fact, one operator mainly assists M. during every atelier and along the whole day while the other one is present just during the afternoon and the night. For this reason the first operator could have more opportunities to experience and report dysfunctional behaviors and delays.

Concerning other results produced by the intervention, it should be pointed out that thanks to the treatment received at the Center, it was possible to notice changes with respect to certain maladaptive behavioral manifestations, such as an overall decrease in hetero-aggressive behaviors due to sudden sounds of human origin (coughing, sneezing), a reduction of hetero-aggressive behaviors caused by the poor tolerance of frustration (demonstrating, thus, an increased ability to sustain waiting times) and the acquisition of more adaptive behaviors such which has made possible, unlike before, the attendance of public places such as playground, supermarkets or shopping centers.

With M., through the Pratique à Plusieurs, it was performed an articulated educational-rehabilitation work. M.'s clinical manifestations have been caught and used as a starting point for the structuring of the ateliers, especially those related to the development of adaptive behaviors and daily skills. During this year and a half of treatment it was given space to the understanding of M.'s behaviors and interests, in order to create, little by little, a place tailored on his characteristics and to enhance, thus, the creation of the subject. It may be concluded that, in this first period, it was necessary to know M., in order to build ateliers that could valorize him, allowing at the same time the modification of maladaptive behaviors shown. Moreover, it must be also taken into account, that the structuring of a temporal and spatial frame, necessary to provide stability to the subject, has allowed $M$. to learn the Community Rules and to manage frustration rather than always searching for immediate satisfaction.

During the treatment, the routine (times, atélier, space) does not change, because space and time structure allows $\mathrm{M}$. and the other guys of the center to find a stable continuity, having a framework of containment. On the other hand the empty container alone, repeated always in the same way, simply ensures the pacification but it does not allow the construction, the learning and the social bond, 
and it is not only the ritual of things which guarantees the subject. This is the reason why, starting from the visiting card of $\mathrm{M}$. the therapeutic equipe have tried to propose more and more complex ateliers as well as different ones, in which other guys were gradually introduced. Only in this way it was possible to increase his skills and ability, and, therefore, also the socialization and interpersonal relationships.

A last issue necessary to be considered, concerns the Guideline 21 (LG21): The treatment of autism spectrum disorders in children and adolescents, published by the Institute of Health in the Strategic Program An epidemiological approach to autism spectrum disorders. This document represents a novelty in the field of research into mental health in childhood and adolescence, aimed to promote greater clarity in the context of treatments, both for operators in the field, and for those who face personally the disorder (LG21, 2011).

The evidence-based methodology on which are based the assumptions of the LG21, finally allows a more scientific perspective in the field of autism, putting an optimistic future Italian research in a modern view, in opposition to the confusion of the past (Casarini, 2012).

The Guidelines 21 (LG21, 2011) show, bringing back experimental and observational studies, that there is clinical efficacy regarding some specific treatments (Treatment and Education of Autistic and Communication Handicapped Children and Applied Behaviour Analysis). However, the actions of psychodynamic matrix for DSA, many times discussed in the literature, are never mentioned in the LG21 (Zappella \& Bertelli, 2012).

Although the results achieved in this study, and in the larger research project, need to be considered a partial perspective and require future research, the idea of legitimizing a psychoanalytic treatment would fill the gap left by the Guideline 21.

Specifically, this research does not presume to confirm the Pratique à Plusieurs as treatment valid and effective as a whole, but must be considered that the Antenna 112, as many other centers that work with this method, are places that exist and that work to improve life quality in children, influencing thus the lived experience of many people.

Furthermore, the results of the research show that improvements are possible thanks to this practice and that, considering, significant variables, the guests of the facility can actually learn to interact with the environment, through new modes of behavior, and change their routine in relation to a new and stimulating context for them.

\section{Conclusions}

Finally it should be considered that the severity of the autism spectrum disorder shared by the children living in this structure, often in conjunction to the delayed diagno- sis received, makes these facilities a sort of last chance for them; for this reason, these significant changes, although minimum, mean a great deal.

\section{References}

American Psychiatric Association (2000). Diagnostic criteria from DSM-IV-TR. Arlington, VA: American Psychiatric Association.

Baio, V. (2011). Non senza genitori. In B. De Halleux (Ed.) "Qualcosa da dire" al bambino autistico (pp. 205-210). Roma: Borla.

Balboni, G., \& Pedrabissi, L. (2003). The Vineland Adaptive Behavior Scale. Adattamento Italiano. Firenze: Organizzazioni Speciali.

Barton, E.E., Lawrence, K., \& Deurloo, F. (2012). Individualizing interventions for young children with autism in preschool. Journal of Autism and Developmental Disorders, 42(6), 1205-1217.

Berument, S.K., Rutter, M., Lord, C., Pickles, A., \& Bailey, A. (1999). Autism screening questionnaire: diagnostic validity. The British Journal of Psychiatry, 175(5), 444-451.

Boudard, B. (2011). Un "programma"? Non senza il soggetto. In B. De Halleux (Ed.). "Qualcosa da dire” al bambino autistico (pp. 105-122). Roma: Borla.

Brousse, M.H. (2011). Ouverture. L'Antenna 110. In B. De Halleux (Ed.). "Qualcosa da dire" al bambino autistico. Roma: Borla.

Bulkeley, K., Bundy, A., Roberts, J., \& Einfeld, S. (2013). ASD intervention research in real world contexts: Refining single case designs. Research in Autism Spectrum Disorders, 7(10), 1257-1264.

Carter, A.S., Volmark, F.R., Sparrow, S.S., Wang, J.J., Lord, C., Dawson, G., Fombonne, E., Loveland, K., Mesibov, G., \& Schopler, E. (1998). The Vineland Adaptive Behavior Scales: supplementary norms for individuals with autism. Journal of Autism and Developmental Disorders, 28(4), 287-302.

Casarini, F. (2012). Di chi è la scienza? Considerazioni a un anno dall'emissione della Linea Guida 21 dell'ISS. Psicologia Clinica Dello Sviluppo, 16(3), 600-602.

Delmolino, L., \& Harris, S.L. (2012). Matching children on the autism spectrum to classrooms: A guide for parents and professionals. Journal of Autism and Developmental Disorders, 42(6), 1197-1204.

Di Ciaccia, A. (2006). Una pratica al rovescio. In F. Tustin (Ed.) Autismo e psicosi infantile (pp. 23-43). Roma: Borla.

Di Ciaccia, A. (2011). Dalla fondazione dell'Uno alla Pratica à Plusieurs. In B. De Halleux (Ed.) "Qualcosa da dire” al bambino autistico (pp. 35-40). Roma: Borla.

Egge, M. (2006). La cura del bambino autistico. Roma: Astrolabio.

Egge, M., \& Grigoletto, C. (2000). Faire une place aux parents. Préliminaire, 13, 105-111.

Emanuel, C. (2015). An accidental Pokemon expert: Contemporary psychoanalysis on the autism spectrum. International Journal of Psychoanalytic Self Psychology, 10(1), 53-68.

Freire, A.B., \& Malcher, F. (2014). What autists can teach us about social interactions and how psychoanalytic treatment can contribute to it. Psychology, 5(11), 1350-1354.

Goin-Kochel, R.P., Myers, B.J., \& Mackintosh, V.H. (2007). Parental reports on the use of treatments and therapies for 
children with autism spectrum disorders. Research in Autism Spectrum Disorders, 1(3), 195-209.

Grandin, T. (2006). Thinking in pictures. My life with autism. New York, NY: Vintage Books, a division of Random House.

LG21 (2011). Linee Guida 21 del Ministero della Sanità. Il trattamento dei Disturbi dello Spettro Autistico nei bambini e negli adolescenti. Available from: www.snlg-iss.it/cms/files/ LG_autismo_def.pdf

Matson, J.L., \& Williams, L.W. (2015). The curious selection process of treatments for Autism Spectrum Disorders. Research in Autism Spectrum Disorders, 9, 21-25.

Maurice, C., Mannion, K., Letso, S., \& Perry, L. (2001). Parent voices: Difficulty in accessing behavioral intervention for autism; working toward solutions. Behavioral Interventions, 16(3), 147-165.

Metz, B., Mulick, J.A., \& Butter, E.M. (2005). Autism: A late20th-century fad magnet. In J.W. Jacobson, R.M. Foxx, \& J.A. Mulick (Eds.) Controversial therapies for developmental disabilities: Fad, fashion and science in professional practice (pp. 237-263). Mahwah, NJ: Lawrence Erlbaum Associates.

Miller, J.A. (2001). Produrre il soggetto? In J.A. Miller (Ed.) I paradigmi del godimento (pp. 165-171). Roma: Astrolabio.

Purgato, N. (2012). Dalla parte degli autistici. Una pratica psicoanalitica integrata. Costruzioni Psicoanalitiche, 24(2), 29-39.

Rutter, M., Bailey, A., \& Lord, C. (2003). The Social Communication Questionnaire: Manual. Torrance, CA: Western Psychological Services.

Rutter, M., Bailey, A., Lord, C., Cianchetti, C., \& Fancello, G.S. (2007). SCQ: Social Communication Questionnaire: Manuale. Firenze: Giunti OS.
Rutter, M., Le Couteur, A., Lord, C., \& Faggioli, R. (2005). ADIR: Autism Diagnostic Interview-Revised: Manual. Firenze: Giunti OS.

Schopler, E., Reichler, R.J., \& Rochen Renner, B.R. (1986). The Childhood Autism Rating Scale for diagnostic screening and classification of autism. New York, NY: Irvington.

Simsek, H.B., \& Koroglu, A.Y. (2012). A study on the demographical characteristics of parents with children diagnosed with autism, problem they face and their knowledge on alternative treatment methods. Procedia-Social and Behavioral Sciences, 47, 577-585.

Sparrow, S.S., Balla, D.A., Cicchetti, D.V. (1984). Vineland Adaptive Behavior Scales. Circle Pines, MN: American Guidance Service.

Stephenson, J., Carter, M., \& Kemp, C. (2012). Quality of the information on educational and therapy interventions provided on the web sites of national autism associations. Research in Autism Spectrum Disorders, 6(1), 11-18.

Strain, P.S., Schwartz, I.S., \& Barton, E.E. (2011). Providing interventions for young children with autism spectrum disorders what we still need to accomplish. Journal of Early Intervention, 33(4), 321-332.

Wong, H.H., \& Smith, R.G. (2006). Patterns of complementary and alternative medical therapy use in children diagnosed with autism spectrum disorders. Journal of Autism and Developmental Disorders, 36(7), 901-909.

Zappella, M., \& Bertelli, M.O. (2012). Linea guida dell'Istituto Superiore di Sanità su "Il trattamento dei disturbi dello spettro autistico nei bambini e negli adolescenti": limiti e implicazioni. Journal of Psychopathology, 18, 322-327. 